\title{
Heat Transmission Effects of Hetero-Material (Al-PZT) Direct Bonding on an In-Pipe Micro Inspection Machine
}

\author{
Member Takaharu Idogaki, Member Hitoshi Kanayama, Member Harumi Suzuki \\ Member Masao Nagakubo and Member Tadashi Hattori
}

\section{(Denso Corporation)}

\section{Summary}

$\mathrm{Al}$ and $\mathrm{PZT}\left\{\mathrm{Pb}(\mathrm{Zr}, \mathrm{Ti}) \mathrm{O}_{3}\right\}$ were directly bondable by forming hydrogen bonds at the interface. The strength of the bond and the structure of the interface were investigated. This technique was applied to the direct bonding between a PZT stacked actuator and an $\mathrm{Al}$ radiator plate on an in-pipe micro inspection machine, and the heat transmission effects of direct bonding on the micro inspection machine have been compared with the adhesive bonding.

First, the $\mathrm{Al}$ and the PZT were treated so that their surfaces were hydrophilic, then $\mathrm{OH}$ groups were adsorbed by a physical reaction in which the surfaces are bombarded with ions produced by passing the steam through anion source. The surfaces were then placed in contact with each other in the air, then heated above $250{ }^{\circ} \mathrm{C}$ in a vacuum to remove the residual water molecules from the bonding interface.

The observation with a thermo-viewer shows that the saturated temperature of the PZT stacked actuator at the driving frequency of $1 \mathrm{kHz}$ is suppressed below $93{ }^{\circ} \mathrm{C}$ by the direct bonding of the $\mathrm{Al}$ radiator plate as compared with $110{ }^{\circ} \mathrm{C}$ of adhesive bonding. Walking speed of the in-pipe micro inspection machine which utilizes the direct bonding was successfully stabilized compared with the adhesive bonding.

\section{Introduction}

Recently, thermally and mechanically low damage direct bonding between dissimilar materials has been becoming the key technology in the field of micromachines, since the conventional bonding methods such as welding and brazing cause the irretrievable damages to the parts constituting of micro mechanisms by the excessive bonding pressure and temperature. On the other hand, adhesives is very convenience and the strength is in applicable range. However, the adhesives obstructs the conduction of heat, electric current and mechanical signal, so that the applicable parts in micromachines is limited. As for the functional micro-parts, the reliability and the stability in the using environment are more important rather than making large the bonding strength.

In this regards, we designed an in-pipe micro inspection machine with a diameter of $6.5 \mathrm{~mm}$ and weight of $1 \mathrm{~g} \mathrm{[1].} \mathrm{This} \mathrm{machine} \mathrm{is} \mathrm{composed} \mathrm{of} \mathrm{mainly}$ three units: a shell-body with a thin plated metal of 60 $\mu \mathrm{m}$ thickness [2], two eddy current sensors that detect the micro cracks of the in-pipe wall and a locomotive mechanism. The locomotive mechanism is composed of three parts: three clamping members that contact the pipe wall elastically to hold the weight of the micro inspection machine and one stacked PZT actuator, and a mass block. The micro inspection machine can move not only in straight butcurved pipes by applying the proper driving frequency to the stacked PZT actuator [3]-[5].

However, the driving characteristics such as the speed and the traction force were affected significantly by the heating of the PZT actuator. When each part of the locomotive mechanism was assembled by conventional adhesives, the temperature of the PZT actuator increased above $110{ }^{\circ} \mathrm{C}$ in a few minutes and the walking speed of the micro inspection machine slowed down with time elapses. Such overheat of the PZT actuator could be caused by the heat conductive obstruction of the adhesive layers. And the lowering of driving characteristics may be due to the change of the piezo-electric properties of the PZT actuator and the worsening of adhesive properties.

From these background, we attempted the direct bonding between $\mathrm{Al}$ plate and PZT stacked actuator. And as the bonding mechanism, the hydrogen bond was selected.

In forming materials, atoms are bonded via covalent bonds, ionic bonds, hydrogen bonds, and van der Waals bonds. Among these, the hydrogen bonds are formed between $\mathrm{OH}$-groups and oxygen atoms. The attraction is originated in the polarization caused by the difference of electronegativity between both atoms of oxygen and hydrogen as shown in Figure 1 [6]. As for the direct bonding between hetero-materials, the 
hydrogen bond is the best candidate due to the wide permitted limit in its angle and distance of bonds. Therefore, many materials that have surface oxide layers are bondable to each other by hydrogen bonds when the $\mathrm{OH}$ groups are adsorbed onto the surfaces [7]. Furthermore, a hydrogen bond has a bonding strength two or three times of a van der Waals bond. Such strength is necessary for the bonding of microparts. In this study, a treatment by the surface bombardment of hydro-ions $\left(\mathrm{H}_{2} \mathrm{O}^{+}, \mathrm{OH}^{+}, \mathrm{O}^{+}\right.$, and others) in vacuum were examined as the surface adsorbing treatment of OH-groups [8]. The bond strength of Al-PZT, the structure of the interface and the heat transmission effects of Al direct bonding on the PZT stacked actuator have been investigated.

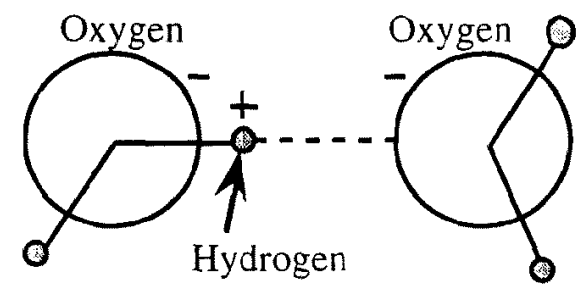

Figure 1. The hydrogen bond between water molecules

\section{Direct Bonding}

\section{2-1 Bonding Treatment}

Al substrates (1.2 mm-thick) are cut from diamond lathed Al plates with a surface roughness factor $(\mathrm{Ra})$ of about $4 \mathrm{~nm}$. The purity of $\mathrm{Al}$ is $95 \mathrm{wt} . \%$ and contains $\mathrm{Mg}(4 \mathrm{wt} \%), \mathrm{Cu}, \mathrm{Si}$ and $\mathrm{Fe}$ for the rest. PZT substrates $(0.45 \mathrm{~mm}$-thick) with a conventional composition are polished until $\mathrm{Ra}$ of about $20 \mathrm{~nm}$. These Al and PZT substrates were used for the measurements of bonding strength. As for the in-pipe micro inspection machine, Figure 2 shows the constituting parts. The size of PZT stacked actuator is $2 \mathrm{~mm} \times 3 \mathrm{~mm} \times 9 \mathrm{~mm}$. The Curie point of PZT is $145{ }^{\circ} \mathrm{C}$. The Al radiator plate is cut to the hexagonal shape from above mentioned Al plates and supports three clamping members. The side length of the hexagonal Al plate is $3.2 \mathrm{~mm}$.

Figure 3 shows the schematic diagram of the hydro-ion bombardment apparatus. The air in the chamber was evacuated until the pressure fell below $3 \times 10^{-4} \mathrm{~Pa}$. After the steam was passed through anion source, the pressure in the chamber was set at $4 \times 10^{-2}$ $\mathrm{Pa}$. The water molecules were ionized in the ion source and the resulting hydro-ions (i.e., $\mathrm{H}_{2} \mathrm{O}^{+}, \mathrm{OH}^{+}, \mathrm{O}^{+}$and others) bombarded the surfaces of the samples, and $\mathrm{OH}$ groups were thus physically adsorbed on the surfaces. The accelerating voltage and the current density of the hydro-ions were set at $300 \mathrm{~V}$ and $125 \mu \mathrm{A} / \mathrm{cm}^{2}$, respectively. The adsorbed number of $\mathrm{OH}$ groups was controlled by the time of the ion bombardment.

During the bonding process, the hydrophilictreated $\mathrm{Al}$ and PZT substrates were placed in contact with each other in the air, then heated to a temperature below $400{ }^{\circ} \mathrm{C}$ in a vacuum chamber. We calculated the bonding strength $(F)$ by dividing the amount of force needed to detach the two substrates (i.e., detachment force) by the bonding area. This detachment force was measured by first fixing the bonded samples to a die using epoxy resin and then pulling the samples in a direction perpendicular to the bonding interface after the resin was set. The force was measured using a load cell.

The OH-groups adsorbed on the surface were analyzed by ERDA(Elastic Recoil Detection Analysis). In this measurement, the differential recoil cross sections of hydrogen on the surface of the sample were determined by $2 \mathrm{MeV} \mathrm{He}^{+}$incidence. The hydrogen profile across the interface between bonded materials was measured by Secondary Ion Mass Spectrometry (SIMS). The elements in the bonding interface were analyzed with etching by $\mathrm{Cs}^{+}$incidence irradiated to the PZT side. The cross-sectional view of the bonding interface is observed by Transmission Electron Microscopy (TEM).

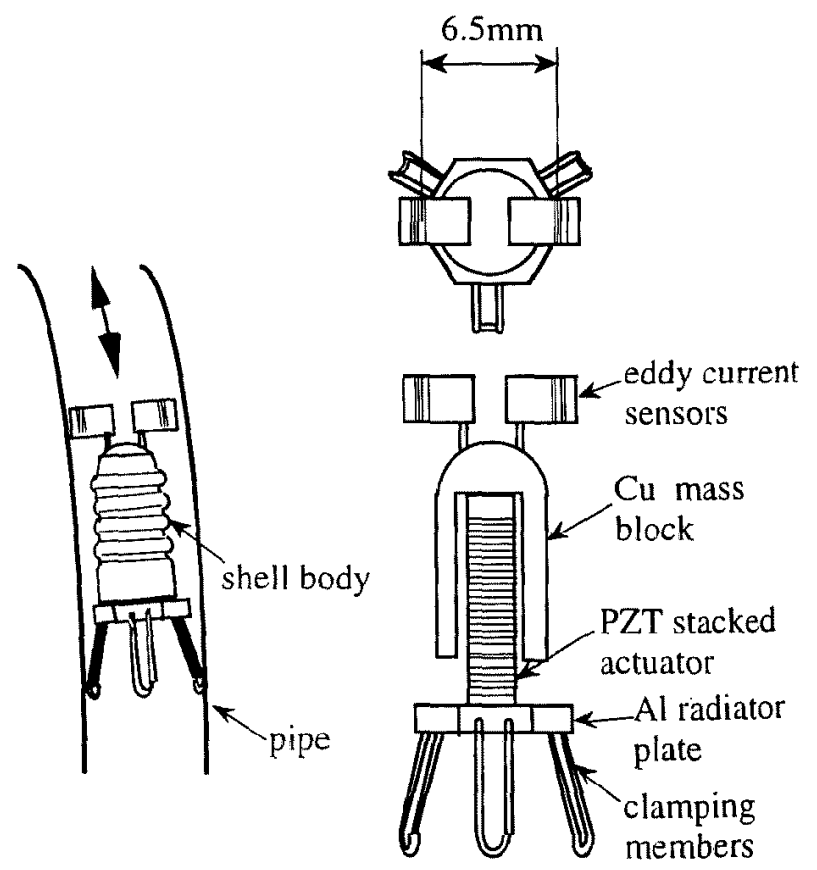

Figure 2. Structure of in-pipe micro inspection machine 
The driving time dependence on temperature of the PZT stacked actuator and the temperature distribution of the actuator were measured by a thermo-viewer (JEOL:JTG-4200) conled by liquid $\mathrm{N}_{2}$. The PZT stacked actuator was suspended by (,$u$ wire $80 \mu \mathrm{m}$ in diameter in the air at room temperature.

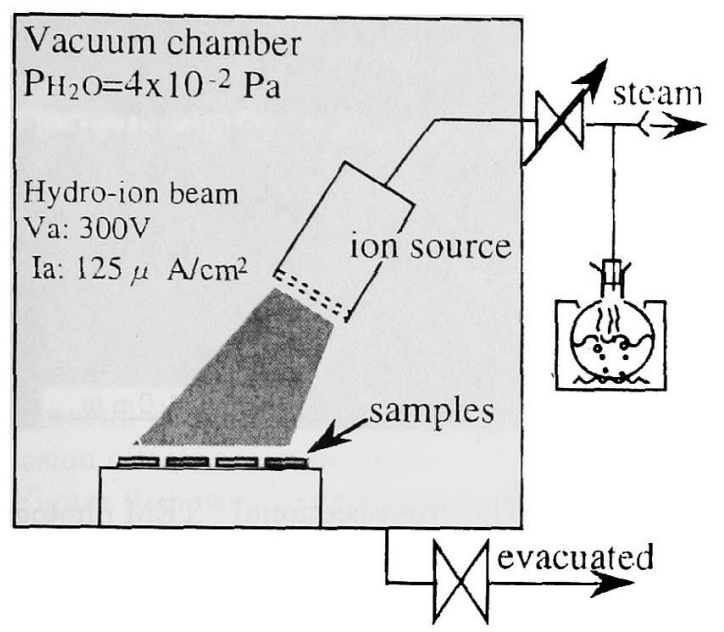

Figure 3. Schematic diagram of a hydro-ion bombardment apparatus

\section{2-2 The Bonding Strength}

$\mathrm{Al}$ and PZT substrates with hydrophilic surfaces are bondable. Figure 4 shows the dependence of the bonding strength of $\mathrm{Al}-\mathrm{PZ}^{\prime} \mathrm{T}$ on the heat treatment time. Then, the temperature of heat treatment and the contacting pressure are set at 400 ${ }^{\circ} \mathrm{C}$ and $30 \mathrm{MPa}$, respectively. When the heating temperature is below $250^{\circ} \mathrm{C}$, the observable bonding strength does not show in these contacting conditions. As shown in Figure 4, the strength increases remarkably at the heat treatment time of above 4 hours, and shows a value of $10 \mathrm{MPa}$ at 5 hours.

Figure 5 shows the photograph of detached sample by tensile measurement. Bonding samples with the strength above $1 \mathrm{MPa}$ are fractured from $\mathrm{PZT}$ side by the pulling force, and the broken pieces of PZT are remained on $\mathrm{Al}$ substrate as shown in Figure 5. On the other hand, when the each surface of Al and PZT is bombarded by argon ions or exposed to no-ionized water molecules in vacuum chamber, any bonding is not observed.

The bonding area of these samples increases with the contacting pressure. Considering that Al substrates have a slight undulation, the increase of bonding area due to contacting pressure could be determined by the degree of deformation corresponding to the applied pressure.

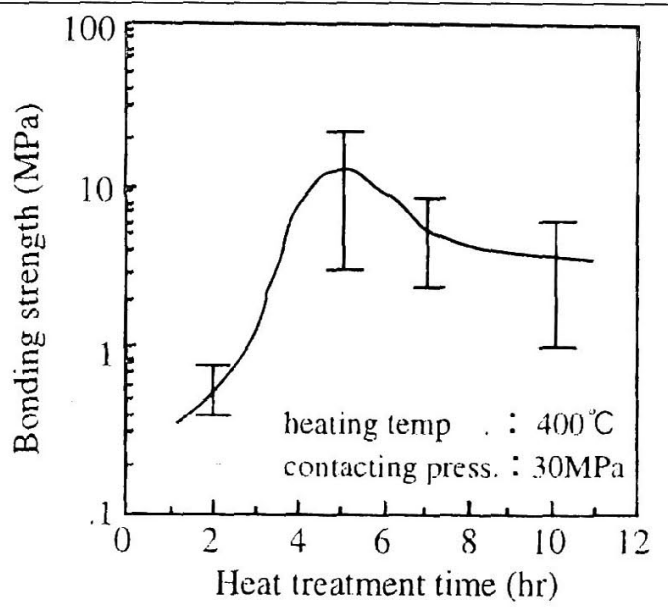

Figure 4. Bonding strength of Al-PZT vs. heat treatment time

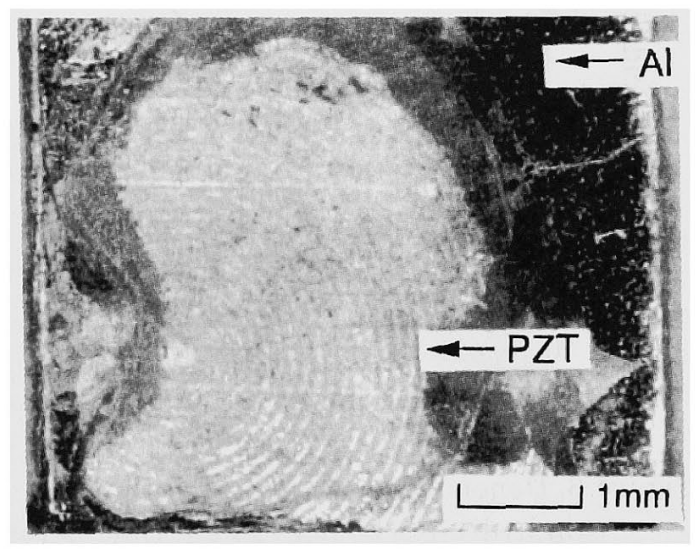

Figure 5. Detached sample by tensile measurement

\section{2-3 The Structure of Bonding Interfa ce}

Figure 6 shows the relation between bombardment time $\left(t_{b}\right)$ and the amount of hydrogen on the surface detected by ERDA(Elastic Recoil Detection Analysis). The increase in hydrogen in the early stages of bombardment $\left(t_{b}<5\right.$ min.) results from the adsorption of $\mathrm{OH}$ groups and water molecules. The saturation when $5 \mathrm{~min}$. $<\mathrm{t}_{\mathrm{b}}<15 \mathrm{~min}$. may show that the surface of the substrate was completely covered by $\mathrm{OH}$ groups and water molecules. Then, adsorption and desorption could be balanced at the substrate surface. The increase when $t_{b}>15$ minutes may relate to the rise in the substrate temperature or to the increase in surface roughness. However, more detailed analysis is necessary to determine the adsorption mechanism in this upper range of $t_{\mathrm{b}}$.

Figure 7(a) shows the cross-sectional SEM photograph of the Al-PZT bonded by the above mentioned direct bonding technique. The temperature of heat treatment and the contacting pressure are 400 ${ }^{\circ} \mathrm{C}$ and $30 \mathrm{MPa}$, respectively. Figure $7(\mathrm{~b})$ shows the 
cross-sectional TEM photograph of the Al-Si bonded by the same method as Al-PZT [8]. The conditions of heat treatment are $400{ }^{\circ} \mathrm{C}$ and 5 hours. The ion bombardment time is 5 minutes. The thickness of oxide layer of bonding interface is estimated about 10 $\mathrm{nm}$ from this photograph. Considering that the growth of Si oxide layer is a little at $400^{\circ} \mathrm{C}$, the observed oxide layer is estimated as $\mathrm{Al}$ oxide layer mainly. It is considered that the heating temperature of $400{ }^{\circ} \mathrm{C}$ is too low to form Al-O-Sibonds by reacting between $\mathrm{SiO}_{2}$ and $\mathrm{Al}_{2} \mathrm{O}_{3}$. Accordingly, it is suggested that the bonding between $\mathrm{Al}$ and $\mathrm{Si}$ is concerned with a hydration reaction between each oxide layer.

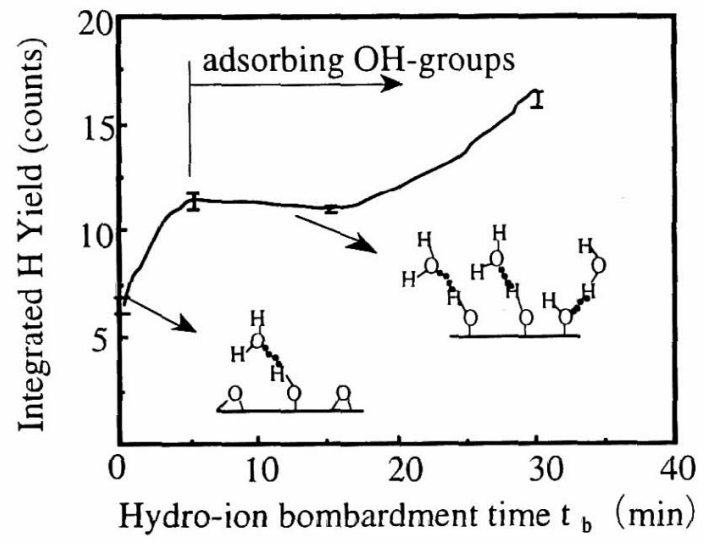

Figure 6. Dependence of integrated H Yield on hydro-ion bombardment time (Al surface)

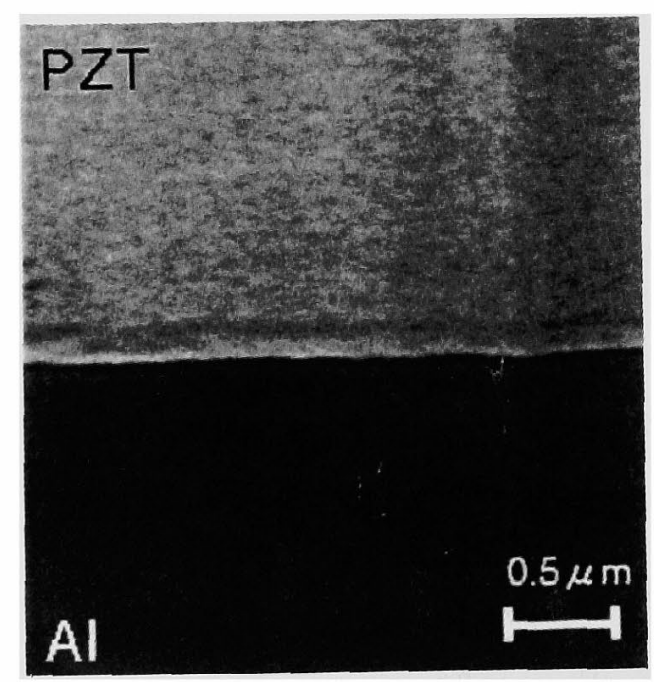

Figure 7 (a). The SEM image of the Al-PZT bonding interface (bonding temperature: $400^{\circ} \mathrm{C}$, contact pressure: $30 \mathrm{MPa}$ )

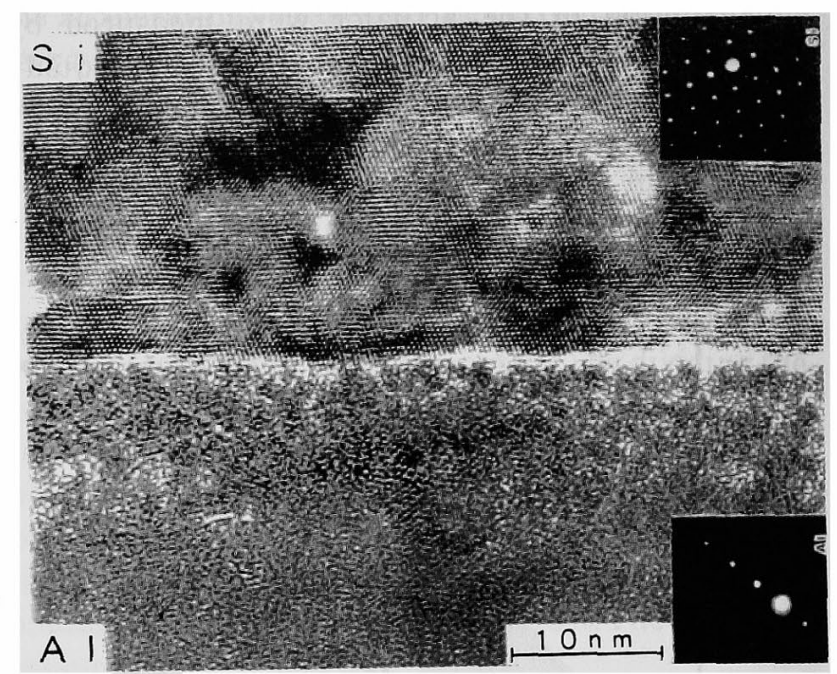

Figure 7(b). The cross-sectional TEM photograph of directly bonded Al-Si.

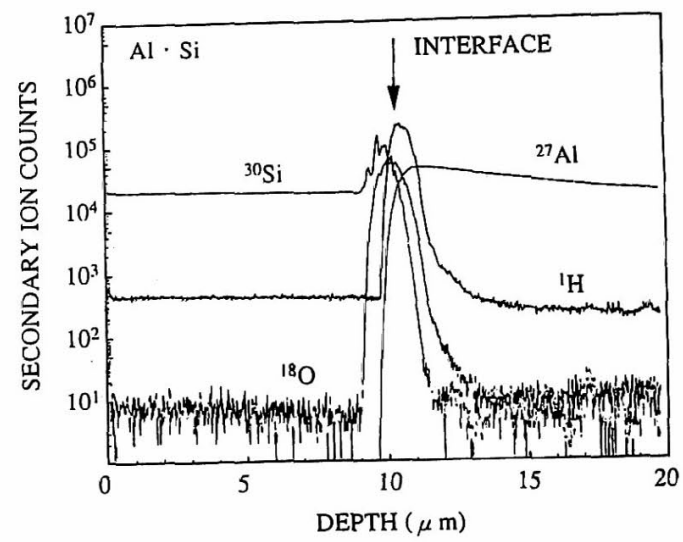

(a)

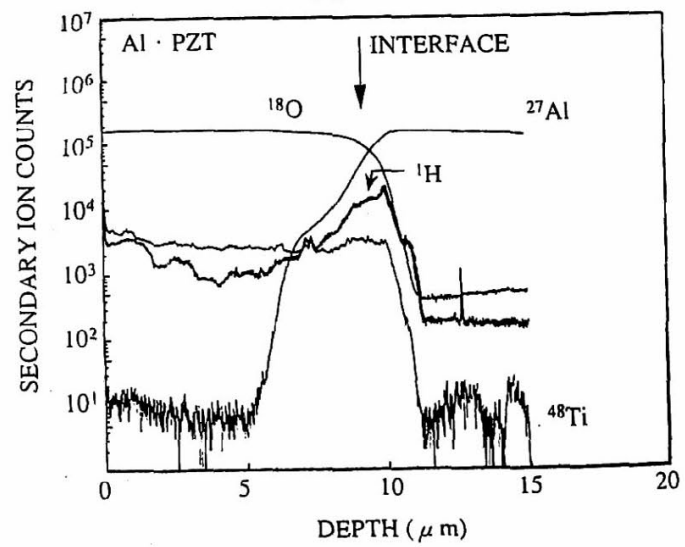

(b)

Figure 8. The depth profile of bonding interface measured by SIMS (a) Al-Si, (b) Al-PZT 
Figure 8 shows the depth profiles of Al-Si (a) and Al-PZT (b) bonding interface measured by SIMS. The bonding conditions are the same as ones of the sample shown in Figure 7. The Si and PZT sides of each samples were ground until the thickness of about 10 $\mu \mathrm{m}$ in advance. The detection of each element is performed by counting of ${ }^{18} \mathrm{O}$ ( existing ratio to ${ }^{16} \mathrm{O}$ is $\left.5 \times 10^{-6}\right),{ }^{1} \mathrm{H},{ }^{30} \mathrm{Si}$ and ${ }^{27} \mathrm{Al}$, respectively. Though the existence ratio of hydrogen to oxygen at just interface can not be decided from this result, the increase of hydrogen at the interface suggests strongly the existence of hydrogen bonds at interface.

\section{Heat Transmission Effects}

Next, an $\mathrm{Al}$ radiator plate and a PZT stacked actuator were directly bonded using above mentioned hetero-material direct bonding technique. Then, heat transmission effects are measured.

Figure 9 shows the driving time dependence on temperature of the PZT stacked actuator, where the driving frequency is $1 \mathrm{kHz}$ of triangular pulse. Black dots show the highest temperature of the PZT stacked actuator when the actuator is bonded to the Al radiator plate with epoxy resin of about $150 \mu \mathrm{m}$ (Cemedine: High Super 5). White dots show the highest temperature of the PZT stacked actuator when the actuator is bonded to the $\mathrm{Al}$ radiator plate with above mentioned hetero-material direct bonding technique. Figure 9 indicates that the temperature saturates about 180 seconds time elapses after applying the driving voltage $100 \mathrm{~V}$ of triangular pulse at the driving frequency of $1 \mathrm{kHz}$.

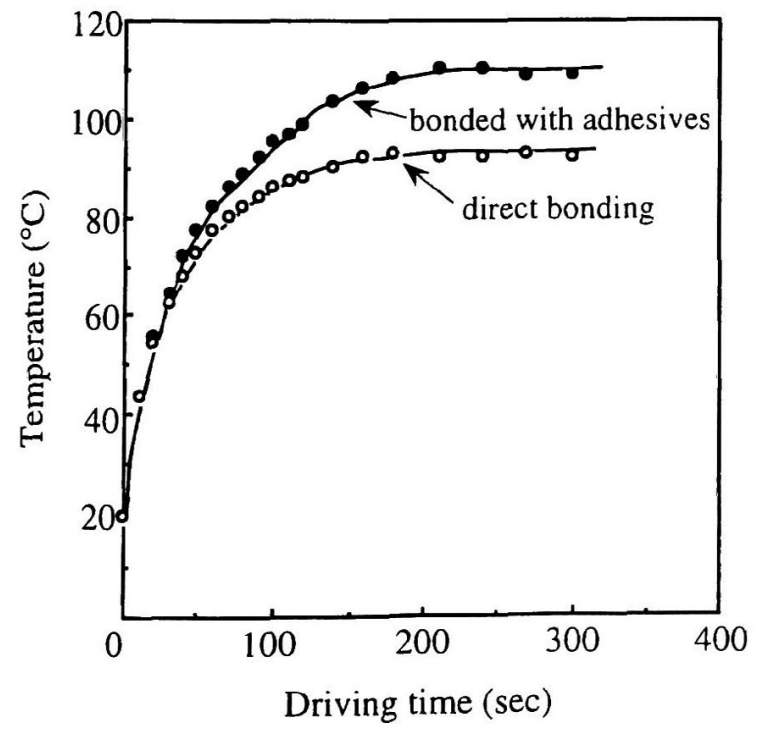

Figure 9. The dependence of temperature of the PZT stacked actuator on the driving time

(driving frequency : $1 \mathrm{KHz}$ )
Figure 10 shows the photographs of the temperature distribution of the P'TT stacked actuator at 300 seconds after applying the driving voltage and frequency. It is observed that the saturated temperature of the P'TI' stacked actuator is suppressed below $93{ }^{\circ} \mathrm{C}$ by the direct bonding of the $\mathrm{Al}$ radiator plate as compared with $110^{\circ} \mathrm{C}$ of adhesive bonding. It is reported that the effective strain of P'I' with the Curie point of $145^{\circ} \mathrm{C}$ is nearly constant from $00^{\circ}($ : to $100^{\circ} \mathrm{C}$, but it decreases in the temperature region over $100^{\circ} \mathrm{C}[9]$. Considering that the Curie point of our $\mathrm{P}^{\prime} Z \mathrm{~T}$ stacked actuator is $145^{\circ} \mathrm{C}$, the walking speed of the in-pipe micro inspection machine which utilizing the PZT stacked actuator could decrease when its temperature is over $100^{\circ} \mathrm{C}$.
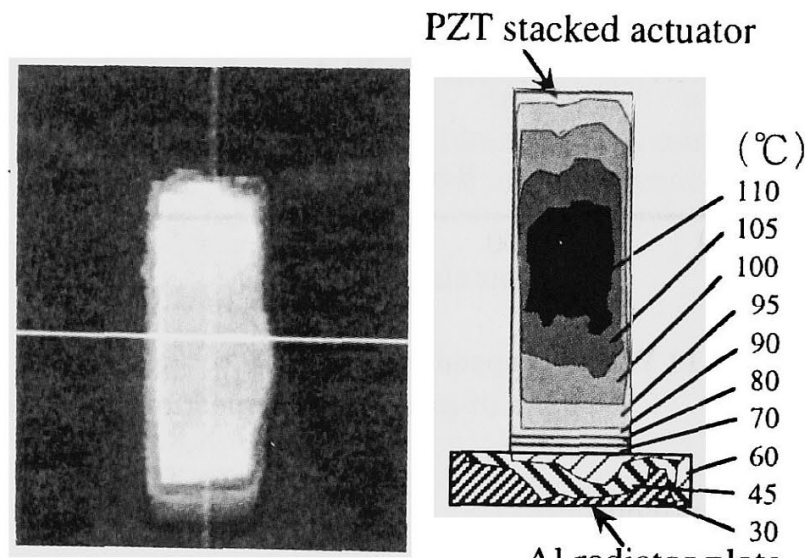

(a)

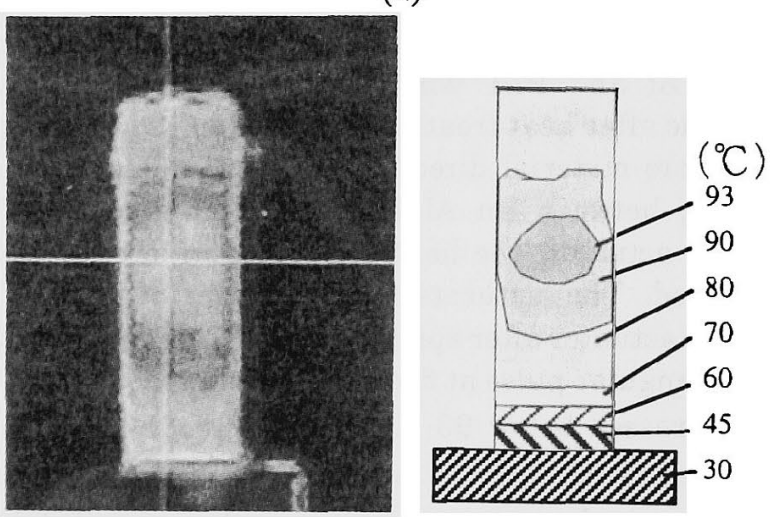

(b)

Figure 10. The temperature distribution of the PZT stacked actuator.

(a) bonded with adhesives, (b) direct bonding. (driving frequency : $1 \mathrm{kHz}$, driving time : 300 second) 
Figure 11 shows the walking speed variation of the in-pipe micro inspection machine described in Figure 2. The walking speed of the micro inspection machine which utilizes the adhesive bonding decreases as the time elapses. On the contrary, the walking speed of the micro inspection machine which utilizes the hetero-material direct bonding technique is stable. The experimental results indicate that the temperature characteristics of the walking speed of the in-pipe micro inspection machine was improved by the heat transmission effect of the hetero-material direct bonding by forming interface hydrogen bonds.

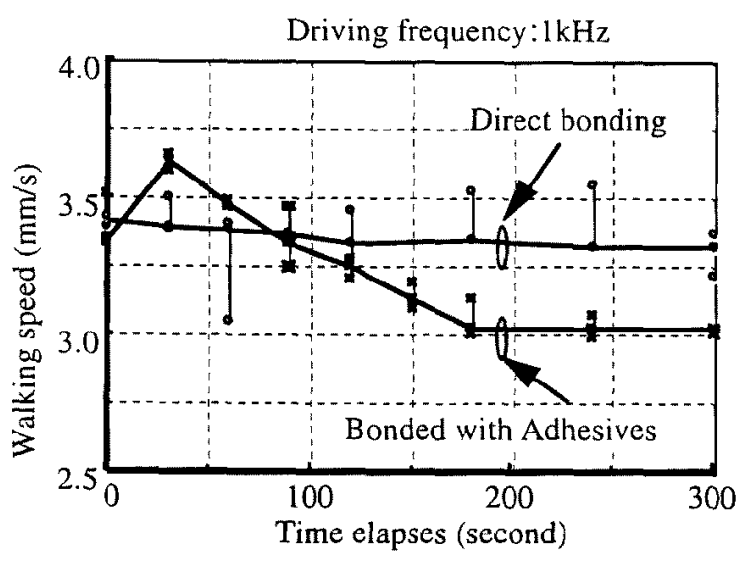

Figure 11 Walking speed variation of the in-pipe micro inspection machine

\section{Con clusion}

The direct bonding by forming interface hydrogen bonds has been examined for Al-PZT. As a result, $\mathrm{Al}$ and PZT with hydrophilic surfaces are bondable after heat treatment above $250^{\circ} \mathrm{C}$. Applying the hetero-material direct bonding technique for the bonding between an $\mathrm{Al}$ radiator plate and a PZT stacked actuator, the heat transmission effects were measured. The saturated temperature of the PZT stacked actuator after applying the driving voltage 100 $\mathrm{V}$ of triangular pulse at the driving frequency of $1 \mathrm{kHz}$ is suppressed below $93{ }^{\circ} \mathrm{C}$ by the direct bonding as compared with $110{ }^{\circ} \mathrm{C}$ of adhesive bonding. The temperature characteristics of the walking speed of the in-pipe micro inspection machine was stabilized by the heat transmission effect of the hetero-material direct bonding by forming interface hydrogen bonds.

\section{Acknowledgments}

This work was performed under the management of Micromachine Center as the
Industrial Science and Technology Frontier Program, "Research and Development of Micromachine Technology", of MITI supported by New Energy and Industrial Technology Development Organization.

(Manuscript received Nov. 11, 1996, revised June 30,1997$)$

\section{References}

[1] T. Idogaki, H. Kanayama, N. Ohya, H. Suzuki and T. Hattori, "Characteristics of Piezoelectric Locomotive Mechanism for an In-Pipe Micro Inspection Machine", Proc. of the Six th International Symposium on Micro Machine and Human Science (Nagoya, Japan, Oct. 1995), pp193-198.

[2]H. Suzuki, N. Ohya, N. Kawahara, M. Yokoi, S. Ohyanagi, T. Kurahashi and T. Hattori, "Shell-body Fabrication for Micromachines", J. Micromech. Microeng. 5(1995), pp36-pp40.

[3]T. Hayashi, "Micromechanism", JSPE-57-01, (1991).

[4]S.F. Bart, T.A. Lober, R.T. Howe, J.H. Lang, M.F. Schlecht, "Design Considerations for Microfabricated Electric Actuators", Sensors and Actuators, Vol.14, No.3, (1988), pp269-292.

[5]T. Higuchi, M. Watanabe, K. Kudou, "Precise Positioner Utilizing Rapid Deformations of a Piezoelectric Element", JSPE-54-11, (1988), pp21072112.

[6]L. Pauling, "The Nature of The Chemical Bond", Cornell University Press., (1960).

[7]M. Nagakubo, K. Senda, S. Fujino and T. Hattori, "Bonding Technique Between Dissimilar Materials by Forming Interface Hydrogen Bridges", Trans. Mat. Res. Soc. Jpn., Vol.16B, (1994), pp1191-1194.

[8]M. Nagakubo, H. Suzuki, T. Idogaki and T. Hattori, "Structures of Bonding Interface by Forming Hydrogen Bridges", Mat. Res. Soc. Symp. Proc. Vol.357, (1995), pp 103-108.

[9] S. Takahashi, "Seimitsu Seigyo-you New Actuator Binran (New Actuators for Precise Control), Fuji Techno Sysytem, Tokyo, (1994), P68 [in Japanese]. 


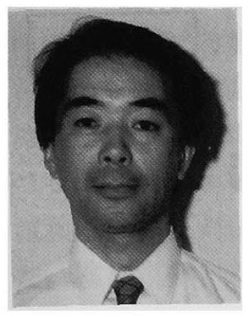

Takaharu Idogaki (member)

$\mathrm{He}$ received his B.S. degree in electronics engineering from Kyoto University in 1978. He joined DENSO CORPORATION and Nippon Soken, Inc., in 1978. In 1992, he joined Micromachine Center. In 1994, he moved to Research Laboratories, DENSO CORPORATION. His research interests are in micromachining, microactuators, microsystems and displays.

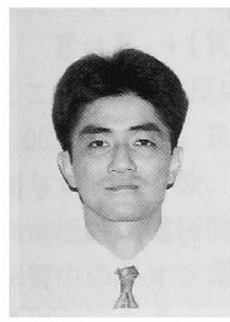

Hitoshi Kanayama (member)

He received his B.S. degree in 1983 and his from Keio University. He joined Nippon Soken, Inc., in 1983 and Research Laboratories, DENSO CORPORATION in 1989. His research interests are in microactuators, displays.

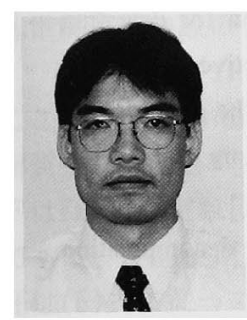

\section{Harumi Suzuki (member)}

He received his B.S. degree in 1990 and his M.E. degree in 1992 from Nagoya University. $\mathrm{He}$ joined Research Laboratories, DENSO CORPORATION in 1992. His research interests are in micromachining, displays.

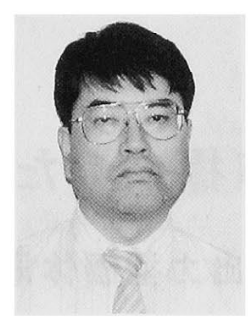

Masao Nagakubo (member)

He received his B.S. degree from Hokkaido University in 1982. He received his doctoral degree from the University of Tokyo Institute of Technology in 1990. He joined Research Laboratories, DENSO CORPORATION in 1991. His research interests are in micromachining, displays.

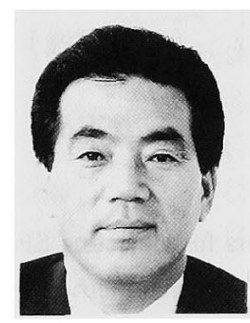

Tadashi Hattori (member)

He received his B.S. degree from Nagoya Institute of Technology in 1967. He received his doctoral degree from the University of Tokyo in 1982. He joined Nippon Soken, Inc., in 1970 and Research Laboratories, DENSO CORPORATION in 1989. His research interests are in micromachining, combustion phenomena, semiconductor sensors, displays. 